\title{
Extracting clearer tsunami currents from shipborne Automatic Identification System data using ship yaw and equation of ship response
}

\author{
Daisuke Inazu ${ }^{1^{*}}\left(\mathbb{D}\right.$, Tsuyoshi Ikeya', Toshio Iseki ${ }^{2}$ and Takuji Waseda ${ }^{3}$
}

\begin{abstract}
We have explored tsunami current signals in maritime Automatic Identification System (AIS) data during the 2011 Tohoku, Japan, tsunami. The AIS data were investigated in detail taking into account ship motion and response to tsunami current. Ship velocity derived from AIS data was divided into two components in terms of the ship heading: heading-normal and heading-parallel directions. The heading-normal velocity showed good agreement with the simulated tsunami current, as mentioned in our former research. Here, we found the heading-normal velocity was contaminated by non-tsunami noises that were mostly related to the ship yaw motion around the pivot point. The noises due to the yaw motion were reasonably corrected in the heading-normal velocity. The corrected headingnormal velocity clearly showed better agreement with the simulated tsunami current. Although the heading-parallel velocity is basically the navigation speed, and is mostly controlled by ships' captain, we could find the heading-parallel velocity was also drifted by tsunami currents. The corrected heading-normal velocity was still a ship response to the tsunami current. Based on an equation of a ship response to tsunami currents, we numerically estimated tsunami current from the corrected heading-normal velocity. We could find very slight improvements in estimating the tsunami currents, which indicated that this operation possibly worked as a secondary correction. Tsunami currents of tens of centimeters per second are expected to be suitably detected using AIS based on discussion on detection limit.
\end{abstract}

Keywords: Tsunami current, Automatic Identification System, Course over ground, Heading, Rate of turn

\section{Introduction}

There are many kinds of observations of tsunamis. We have mostly measured sea surface elevation for quantitative evaluations (Satake 2007; Joseph 2011). Measuring sea surface height is fundamental to understand and utilize the oceans. Many practical methods have been developed and utilized to measure sea levels including tsunamis (IOC 2006). Measuring water surface levels in coastal tide wells has a long history (Satake et al. 1988; Rabinovich et al. 2006; Namegaya et al. 2009). Aerial

\footnotetext{
*Correspondence: inazud@m.kaiyodai.ac.jp

${ }^{1}$ Department of Marine Resources and Energy, Tokyo University of Marine

Science and Technology, 4-5-7 Konan, Minato, Tokyo 108-8477, Japan

Full list of author information is available at the end of the article
}

acoustic waves and/or frequency-modulated continuous waves (FMCW) reflected at the sea surface are used to detect water surface location (Míguez et al. 2005; Joseph 2011; Woodworth 2016). A floating buoy with a Global Navigation Satellite System (GNSS) receiver has been able to measure water surface position (Chadwell and Bock 2001; Kawai et al. 2013; Kato et al. 2018). A coastal GNSS station can detect water surface with coherent direct and reflected rays (Anderson 2000; Löfgren and Haas 2014; Larson et al. 2017). Methods from below sea level and sea bottom are utilized as well. Bubble gauges were used to estimate water column height based on hydrostatic pressure equilibrium (Pugh 1972; Woodworth and Smith 2003). Travel time of ultrasonic wave 
reflection is used to measure the distance between sea bottom and sea surface (Takayama et al. 1994; Hashimoto et al. 1996). Pressure gauges at the deep-sea bottom feel the total water column height above the seafloor (Filloux 1983; Eble and Gonzalez 1991; Hino et al. 2013). There are satellite communication systems such as the Deepocean Assessment and Reporting of Tsunamis (DART) system (Bernard et al. 2006; Mungov et al. 2013), and seafloor cable systems such as NEPTUNE Canada, DONET, and S-net (Rabinovich and Eblé 2015; Kaneda et al. 2015; Kanazawa et al. 2016). These are based on fixed-point observations.

Meanwhile, moving-point observations have been increasingly considered as well. Satellite altimetry has actually detected tsunamis (Okal et al. 1999; Godin et al. 2009; Song et al. 2012). Aircraft radar altimetry will be able to detect tsunamis (Wright et al. 2009; Hirobe et al. 2019; Mulia et al. 2020). GNSS-reflectometry using flying vehicles will be used to measure sea surface heights including tsunamis. Reflection receivers widely include low Earth orbit (LEO) satellites (Clarizia et al. 2016; Wickert et al. 2016; Mashburn et al. 2018), manned aircraft (Lowe et al. 2002; Ruffini et al. 2004; Cardellach et al. 2014), and unmanned aerial vehicles (Ichikawa et al. 2019). GNSS attached to a seagoing ship could detect a $10-\mathrm{cm}$ tsunami height (Foster et al. 2012) because the GNSS positioning involved $\sim 10-\mathrm{cm}$ precision (Foster et al. 2009). If ordinary GNSS facilities with meter-order precision attached to present commercial ships were replaced by such high-precision GNSS facilities, geophysical signals as well as tsunamis would be detectable from many unspecified ships (Roggenbuck et al. 2014; Inazu et al. 2016).

Tsunamis involve water currents mostly in the horizontal direction. The water currents due to tsunamis have been measured by acoustic Doppler current profilers (ADCPs) at fixed points (Bricker et al. 2007; Lacy et al. 2012; Sobarzo et al. 2012). Terrestrial high-frequency (HF) radar has been used to spatially cover horizontal water currents within tens of kilometers from the radar stations (Hinata et al. 2011; Benjamin et al. 2016; Dzvonkovskaya et al. 2018). These facilities are mostly deployed for the purpose of monitoring coastal ocean circulations with wide applications (Roarty et al. 2019).

Inazu et al. (2018) found that tsunami currents could be detected using navigation data derived from the Automatic Identification System (AIS). They demonstrated a feasibility of tsunami detectors from crowd-sourced moving vessels. If shipborne ADCP data are widely shared, ocean currents including tsunamis will be suitably detected at moving vessels (Horiuchi et al. 2015; Miyazawa et al. 2015). However, according to the current maritime convention (IMO 2016), AIS does not include
ADCP facilities and data. Such data can be only aggregated from specified vessels. On the other hand, AIS data are aggregated from a large number of unspecified vessels thanks to regulations of the International Maritime Organization (IMO 2016). We have investigated this versatile AIS for tsunami current measurements (Inazu et al. 2018). In the present study, a more efficient method incorporating ship motions is demonstrated to detect clearer tsunami currents.

\section{AIS data}

We use AIS data during the 2011 Tohoku, Japan, tsunami, which are the same data as used in the authors' former research (Inazu et al. 2018). Based on the International Convention for the Safety of Life at Sea (SOLAS), vessels whose gross tonnages are basically greater than 300 gross tonnages have obligation to transmit AIS messages using very-high-frequency (VHF) maritime bands (IMO 2002, 2016). Transmitted AIS messages can be received by terrestrial stations with $<\sim 100 \mathrm{~km}$ distances, and be received by LEO satellites (Høye et al. 2008; Eriksen et al. 2010; Carson-Jackson 2012). In March 2011, around Japan, there were only terrestrial AIS data available. Temporal sampling of transmitted AIS messages is typically tens of seconds during navigation. A formatted sentence of AIS includes dynamic and static information. Dynamic information includes time, horizontal position (latitude/longitude), speed over ground (SOG), course over ground (COG), ship heading (HDG), and so on. Static information includes Maritime Mobile Service Identity (MMSI), ship type, ship name, and so on. The requirement for the AIS format was given by the IMO Maritime Safety Committee (IMO 1998). Specifications are defined in documents of the International Telecommunication Union (ITU) and the International Electrotechnical Commission (IEC). They have been sometimes updated, and recent versions are shown in ITU (2014) and IEC (2018). Brief descriptions are also available (Tetley and Calcutt 2001; Masuda et al. 2014; IMO 2016). There are almost real-time ship distributions derived from AIS data available on websites such as MarineTraffic (https://www. marinetraffic.com), VesselFinder (https://www.vesselfind er.com), Shipfinder (http://jp.shipfinder.com/Monitor), and so on.

Regarding the precision of position of the AIS transponder, Differential GNSS (DGNSS) correction (i.e., Msg. 17) is suitably applied when the AIS transponder can find an available reference station. Ordinary GNSS single-point positioning is applied if there is no available station (IEC 2018). When DGNSS correction is applied, positioning precision is expected to be $<10 \mathrm{~m}$. Resolution of the heading direction derived from compass seems not to be strictly determined (IEC 2018). In most cases in AIS 
data, HDG and COG are obtained in 1.0 and 0.1 degrees, respectively.

Figure 1 shows the ship distribution during the 2011 Tohoku tsunami derived from the AIS data. All the identified vessels were $>300$ gross tonnages. Smaller vessels such as fishery boats were not included in the AIS data although there were probably a great number of such smaller vessels. At offshore regions of Iwate and Fukushima, AIS data could be retrieved at terrestrial stations during $<45$ min after the earthquake generation. Meanwhile, offshore of Miyagi, AIS data received at terrestrial stations were lost immediately (a few minutes) after the earthquake generation probably because of power failure due to the strongest ground motion near the epicenter. As shown in Inazu et al. (2018), we found 16 ships navigating offshore Tohoku (depth $>\sim 100 \mathrm{~m}$ ), and clear tsunami current signals from 13 ships (\#1-\#13) (Table 1). These ships actually experienced tsunami currents far greater than $0.1 \mathrm{~m} / \mathrm{s}$, as also indicated by tsunami simulation (Fig. 1).

The AIS data are investigated in detail (Fig. 2). SOG, COG and HDG are obtained from AIS records in addition to the time and position. In principle, SOG and COG are calculated from the time derivative of the ship positions. HDG is obtained by gyro/ magnetic compass. The rate of turn (ROT) or angular velocity of the ship is obtained from the time derivative of HDG. The HDG-normal velocity (sway $\left.v_{\mathrm{n}}=\mathrm{SOG} \sin (\mathrm{COG}-\mathrm{HDG})\right)$ is calculated as well as

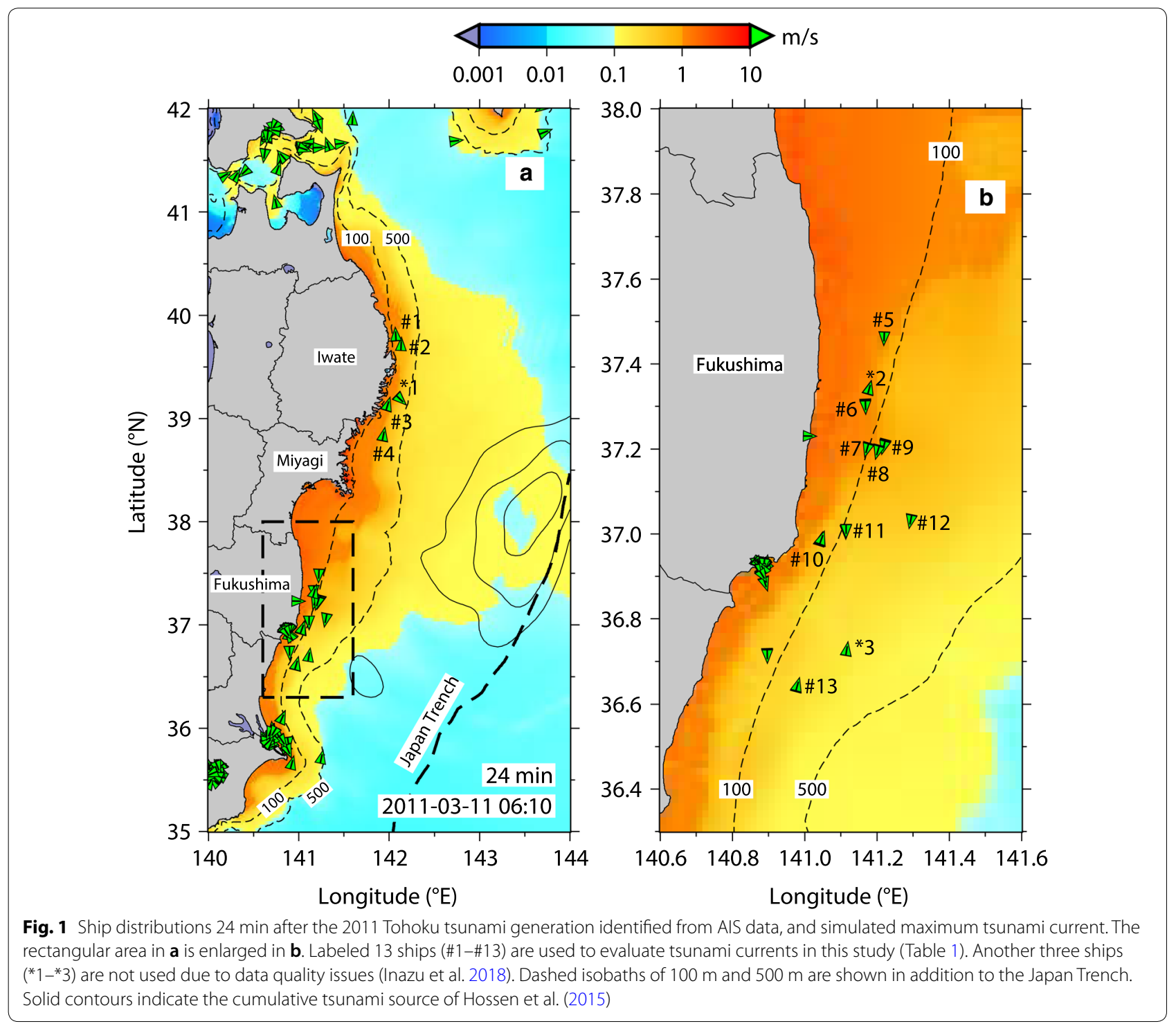


Table 1 Ship information and standard deviations derived from AIS data, except for gross tonnage, which was taken from MarineTraffic (https://www.marinetraffic.com/)

\begin{tabular}{|c|c|c|c|c|c|c|c|}
\hline \multirow[t]{2}{*}{$\mathrm{ID}^{\mathrm{a}}$} & \multirow[t]{2}{*}{ Vessel type } & \multirow[t]{2}{*}{ Gross tonnage } & \multirow[t]{2}{*}{ Draught (m) } & \multirow[t]{2}{*}{ Length $(\mathrm{m})$} & \multirow[t]{2}{*}{ Breadth $(\mathrm{m})$} & \multicolumn{2}{|c|}{ Standard deviations $\mathbf{s}^{\mathbf{b}}$} \\
\hline & & & & & & $\begin{array}{l}\text { COG-HDG } \\
\text { (deg.) }\end{array}$ & $V(\mathrm{~m} / \mathrm{s})$ \\
\hline$\# 1$ & Cargo & 1658 & 5.0 & 98.52 & 15.0 & 0.68 & 0.081 \\
\hline$\# 2$ & Cargo & 499 & 4.5 & 74.71 & 12.0 & 0.57 & 0.057 \\
\hline \#3 & Tanker & 2998 & 6.4 & 104.81 & 15.5 & 0.49 & 0.051 \\
\hline$\# 4$ & Cargo & 8566 & 5.3 & 119.5 & 20.4 & 0.67 & 0.073 \\
\hline \#5 & Tanker & 3319 & 4.5 & 99.8 & 15.8 & 1.04 & 0.078 \\
\hline$\# 6$ & Cargo & 14,790 & 7.5 & 167 & 30.2 & 0.51 & 0.103 \\
\hline \#7 & Tanker & 748 & 4.5 & 74.99 & 11.5 & 0.33 & 0.035 \\
\hline \#8 & Tanker & 3869 & 4.8 & 104.94 & 16.0 & 0.50 & 0.063 \\
\hline \#9 & Cargo & 12,526 & 6.7 & 199 & 24.5 & 0.48 & 0.089 \\
\hline$\# 10$ & Tanker & 414 & N/A & 57.29 & 10.0 & 0.73 & 0.067 \\
\hline$\# 11$ & Cargo & 3692 & 6.3 & 115 & 20.0 & 0.32 & 0.045 \\
\hline$\# 12$ & N/A & 499 & 4.0 & 76.2 & 13.0 & 0.76 & 0.083 \\
\hline \multirow[t]{2}{*}{$\# 13$} & Cargo & 748 & 5.0 & 83 & 14.0 & 0.61 & 0.057 \\
\hline & & & & & Average & 0.59 & 0.068 \\
\hline
\end{tabular}

a Serial IDs are used instead of MMSIs to protect vessel privacy

b Standard deviations are calculated from time series during $2 \mathrm{~h}$ before the tsunami generation (Figs. $4 \mathrm{~b}$ and $6 \mathrm{~b}$ )

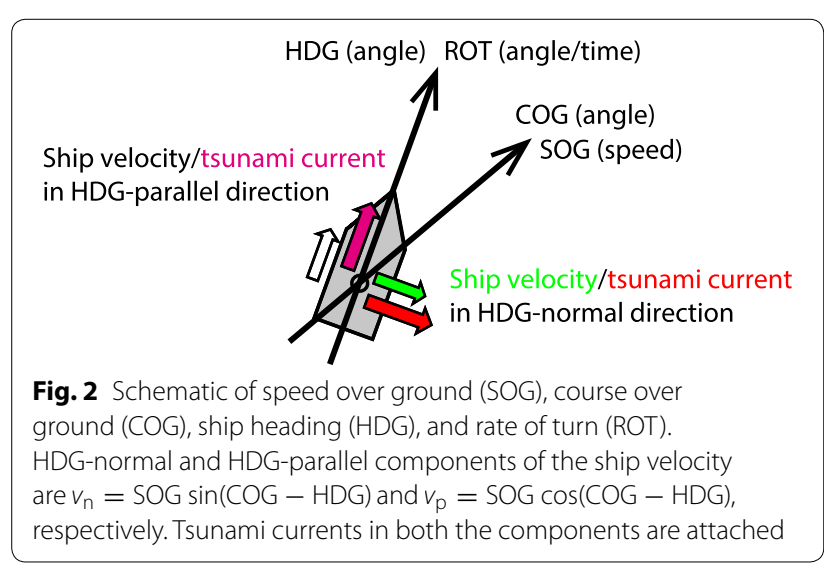

Inazu et al. (2018). The HDG-parallel velocity (surge $\left.v_{\mathrm{p}}=\mathrm{SOG} \cos (\mathrm{COG}-\mathrm{HDG})\right)$ is also calculated.

Figure 3 shows ship velocity and simulated tsunami current in the HDG-normal direction. Initial condition or generation process of the tsunami is a crucial factor for the tsunami simulation result. Simulation results using two initial conditions are compared. One is given by Saito et al. (2011) which estimated an instant tsunami generation. The result was used in Inazu et al. (2018). The other is given by Hossen et al. (2015) which estimated a dynamic tsunami generation during $3 \mathrm{~min}$. Both simulation models well represent $v_{\mathrm{n}}$. Saito et al. (2011) fail to correlate \#1 but correlate well \#5 (Fig. 3a). Meanwhile Hossen et al. (2015) correlate well \#1 but fail to correlate \#5 (Fig. 3b). Overall correlation coefficients are equivalent as much as $0.72-0.73$ derived from both the models. Both the models were previously compared by Baba et al. (2017), and the model of Hossen et al. (2015) was able to show possibly better waveforms in both near- and farfield stations in the Pacific Ocean. In the present study, the simulation result derived from Hossen et al. (2015) is mainly used to examine the AIS data. The simulation result derived from Saito et al. (2011) is complementally used to evaluate sensitivities of the analyses (Additional file 1: Figs. S2 and S3).

The AIS data are shown with the tsunami simulation in Fig. 4 and Additional file 1: Fig. S1. The AIS data shown are averaged over a 1-min time window, and resampled by 0.25 min. As shown in Fig. 3, the HDG-normal velocity $\left(v_{n}\right)$ is a good proxy of tsunami currents in this direction. According to theoretical considerations by Inazu et al. (2018), it is reasonable that the HDG-normal velocity immediately (<a few minutes) responds to longwave tsunami currents with equivalent speeds. Here, the HDG-parallel velocity $\left(v_{\mathrm{p}}\right)$ is evaluated as well. The HDGparallel velocity is basically recognized as forward speed of ship (Fig. 4e, f). According to the major tsunami warning which was first issued 3 min and next updated $28 \mathrm{~min}$ after the earthquake generation (Tsushima et al. 2011; Ozaki 2012), captains of ships had to carefully judge how the tsunami came. Several ships perhaps adjusted to 

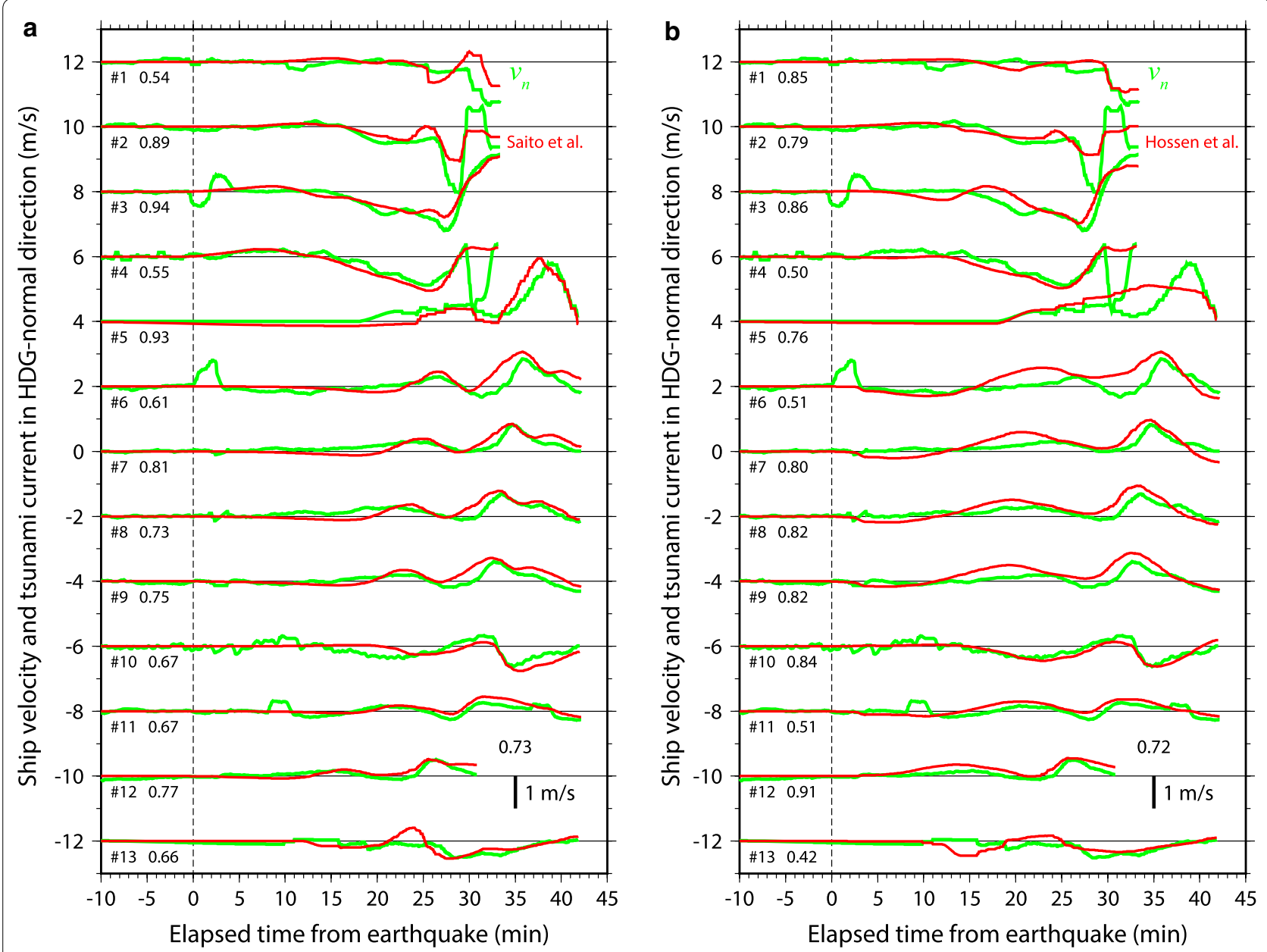

Fig. 3 Ship velocity (green) and simulated tsunami current (red) in the HDG-normal direction for the 13 ships. The simulations are carried out using the initial conditions of a Saito et al. (2011) and b Hossen et al. (2015), respectively. The plots in a is the same as Fig. 5 of Inazu et al. (2018). Correlation coefficients between the ship velocity and the simulations are attached for the respective ships. Mean correlation coefficient is shown at lower right of each panel

decrease their speeds $(\# 3, \# 6, \# 7, \# 10$, and \#12) after the first tsunami warning. Several ships (\#3, \#11, and \#12) also decreased their speeds around the next update of the tsunami warning (Fig. 4 and Additional file 1: Fig. S1). Thus, captains of these ships probably controlled their speeds or the HDG-parallel velocities. It is difficult to distinguish the tsunami and man-made control in the HDGparallel velocity. Nevertheless, ships such as \#1, \#2, and \#5, where man-made controls seem not drastic, clearly showed that the HDG-parallel velocities were drifted by tsunami currents with equivalent amplitudes (Fig. $4 \mathrm{e}$ and Additional file 1: Fig. S1). This indicates that the response of the HDG-parallel velocity to the tsunami currents is qualitatively similar to that of the HDG-normal velocity.

\section{Rate of turn and heading-normal velocity}

There are still non-tsunami deviations in the HDG-normal velocity (e.g., \#3 and \#11 in Fig. 4d). When the HDGnormal velocity is used as a tsunami current meter, such deviations will be significant noises. Here, we considered ROT derived from the time derivative of HDG, and found clear (negative) correlations between ROT and the HDG-normal velocity (Fig. 4c, d).

We try to understand the relationship of the negative correlation employing a simplified model (Fig. 5) in which a vessel moving forward steers rightward in a calm ocean. First, the vessel is moving forward. HDG should be the same as COG (Fig. 5a). Second, the vessel is abruptly steering rightward or yawing clockwise. When HDG is increasing, ROT is positive. Probably, 


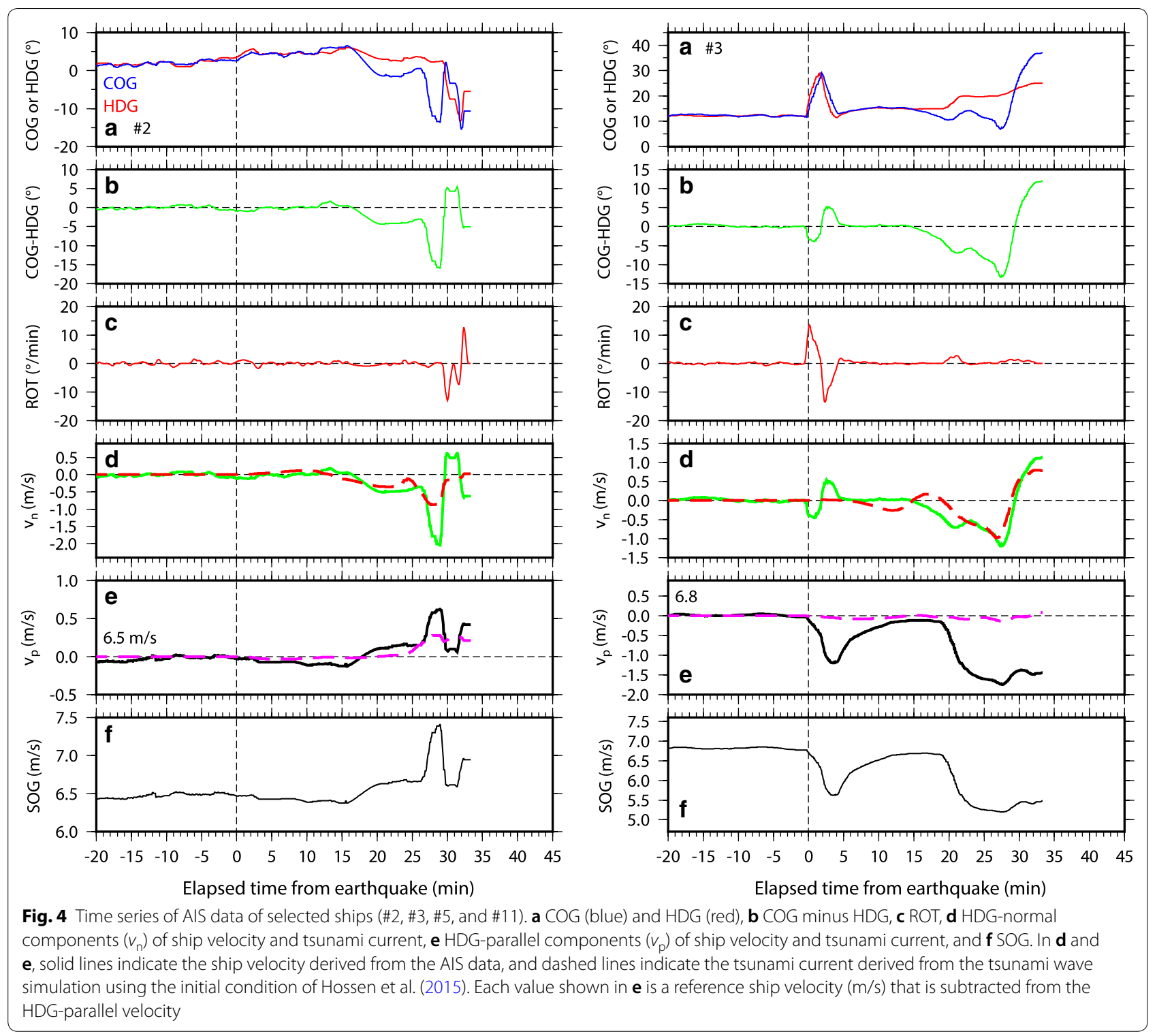

COG is left behind HDG just after steering (Fig. 5b). Thereafter COG catches up with HDG (Fig. 5c).

While the pivot point of a stopped ship is located at the center of mass of the ship, the pivot point of a ship moving forward is moving forward as well (Tzeng 1998; Clark 2005; Seo and Mishu 2011). In addition, a GNSS antenna is usually attached near the navigation bridge, and the bridge is located at the back for many ships, in particular for ordinary commercial ships such as cargo ships and tankers (Chihara 1969). Ship position and COG are strictly related to the location of the GNSS antenna. Thus, the rotation axis of HDG (i.e., pivot point) and the rotation axis of COG are separated by a distance comparable to the ship length. So, there is an apparent sway motion during yawing (Fig. 5). The apparent sway speed is

$$
v_{s}=-\mathrm{ROT} \times A \times L,
$$

where $L$ is the ship length. $A$ is a coefficient which seems mostly to be 1.0 but may be variable. When ROT is positive (i.e., HDG is increasing), $v_{\mathrm{s}}$ indicates negative direction of the heading-normal velocity (Figs. 2 and $5 \mathrm{~b}$ ). It is known that, when an advancing ship turns its heading, the pivot point moves forward to keep the circle radius of the pivot-point trajectory effectively shorter than that of the center of mass trajectory (Seo and Mishu 2011). The essence of the apparent sway has been known in turning circle tests in naval architectures (Kijima et al. 

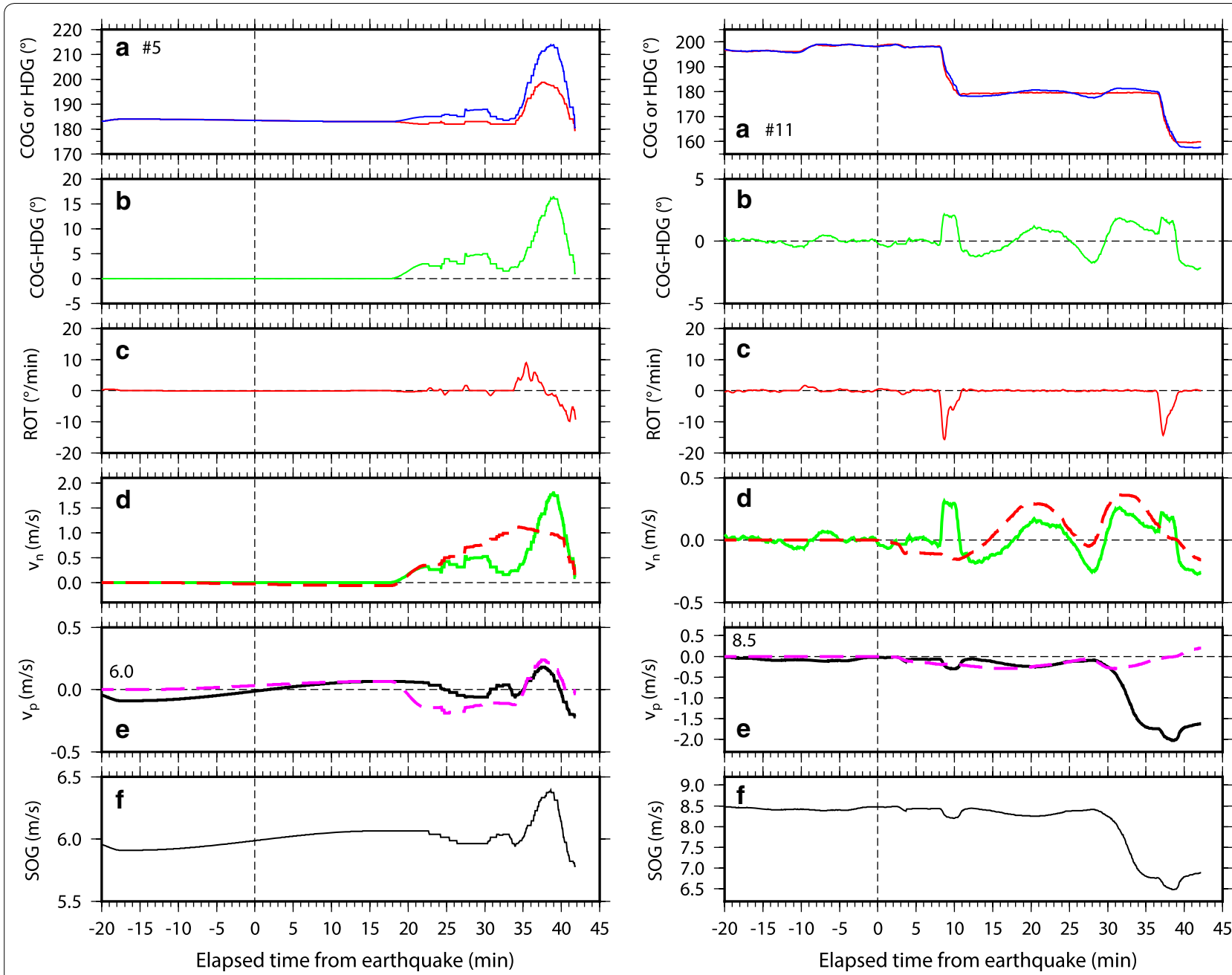

Fig. 4 continued

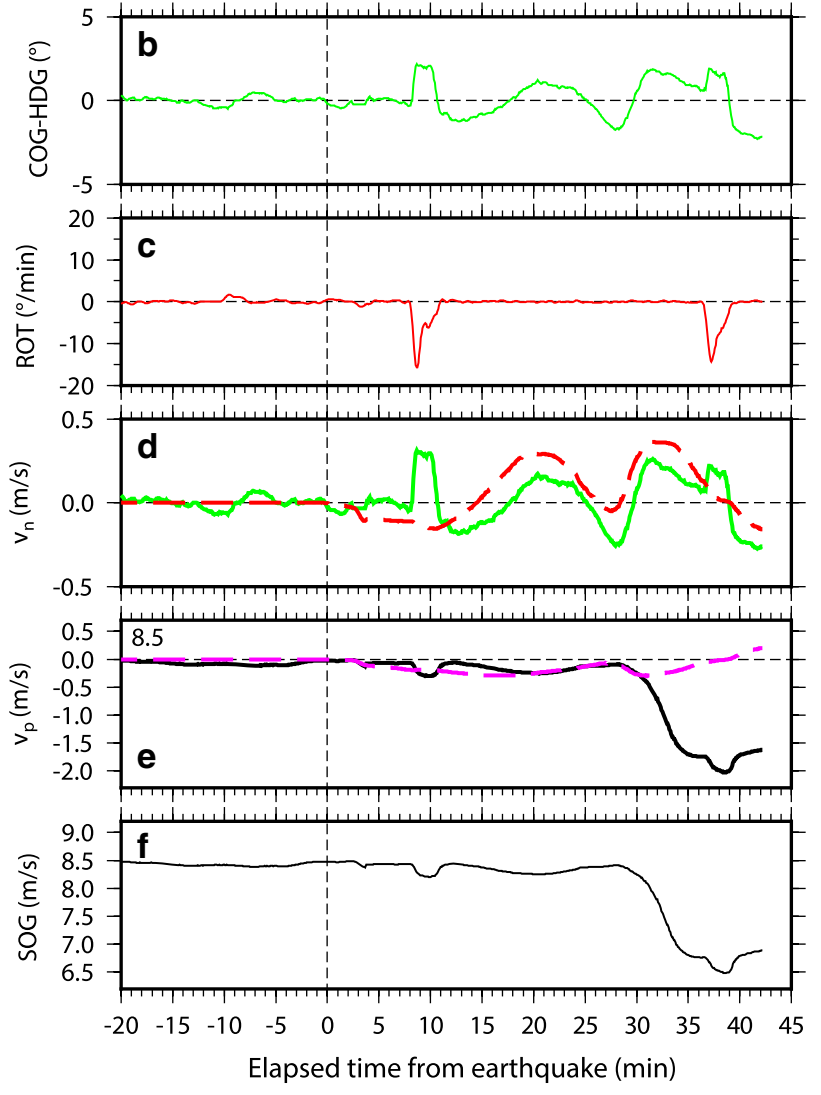

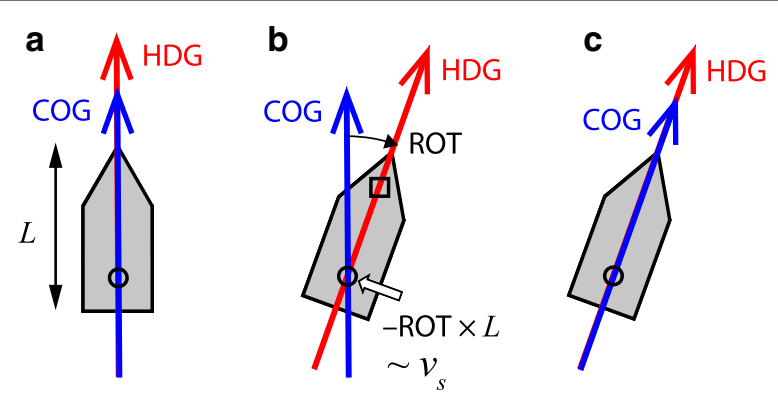

Fig. 5 Schematic diagram of apparent sway velocity $\left(v_{s}\right)$ due to ship yawing of forwarding ship whose ship length is $L$. Open square and open circles indicate the pivot point of the ship and the GNSS antenna, respectively

1990; Yoshimura and Ma 2003; Yoshimura and Masumoto 2011) in which $A \sim 1.0$ corresponds to the distance between the pivot point and the rudder at stern.
We find good agreement between the HDG-normal velocity $\left(v_{\mathrm{n}}\right)$ and the apparent sway velocity $\left(v_{\mathrm{s}}\right)$ in particular before tsunami arrival times (Fig. 6a). The components derived from ROT are well corrected from the HDG-normal velocity, in particular for several ships of \#3, \#4, \#6, and \#11 (Fig. 6b). The corrected HDG-normal velocity $\left(v=v_{\mathrm{n}}-v_{\mathrm{s}}\right)$ shows better agreement with the simulated tsunami currents $\left(v_{c}\right)$. Correlation coefficients between $v_{\mathrm{n}}-v_{\mathrm{s}}$ and $v_{c}$ (mean value of 0.78) become greater than those between $v_{\mathrm{n}}$ and $v_{c},(0.72)$ for almost $(11 / 13)$ of the ships (Figs. 3b and $6 \mathrm{~b})$. Such improvements in the correlation coefficients are also found for $10 / 13$ ships when tsunami simulation employed the initial condition of Saito et al. (2011) (Fig. 3a and Additional file 1: Fig. S2). The mean correlation coefficient similarly increases to 0.78 from 0.73 . These indicate that the correction using ROT robustly removes non-tsunami components in the AIS data. For the 2011 Tohoku tsunami, tsunami signals were evident without the correction 

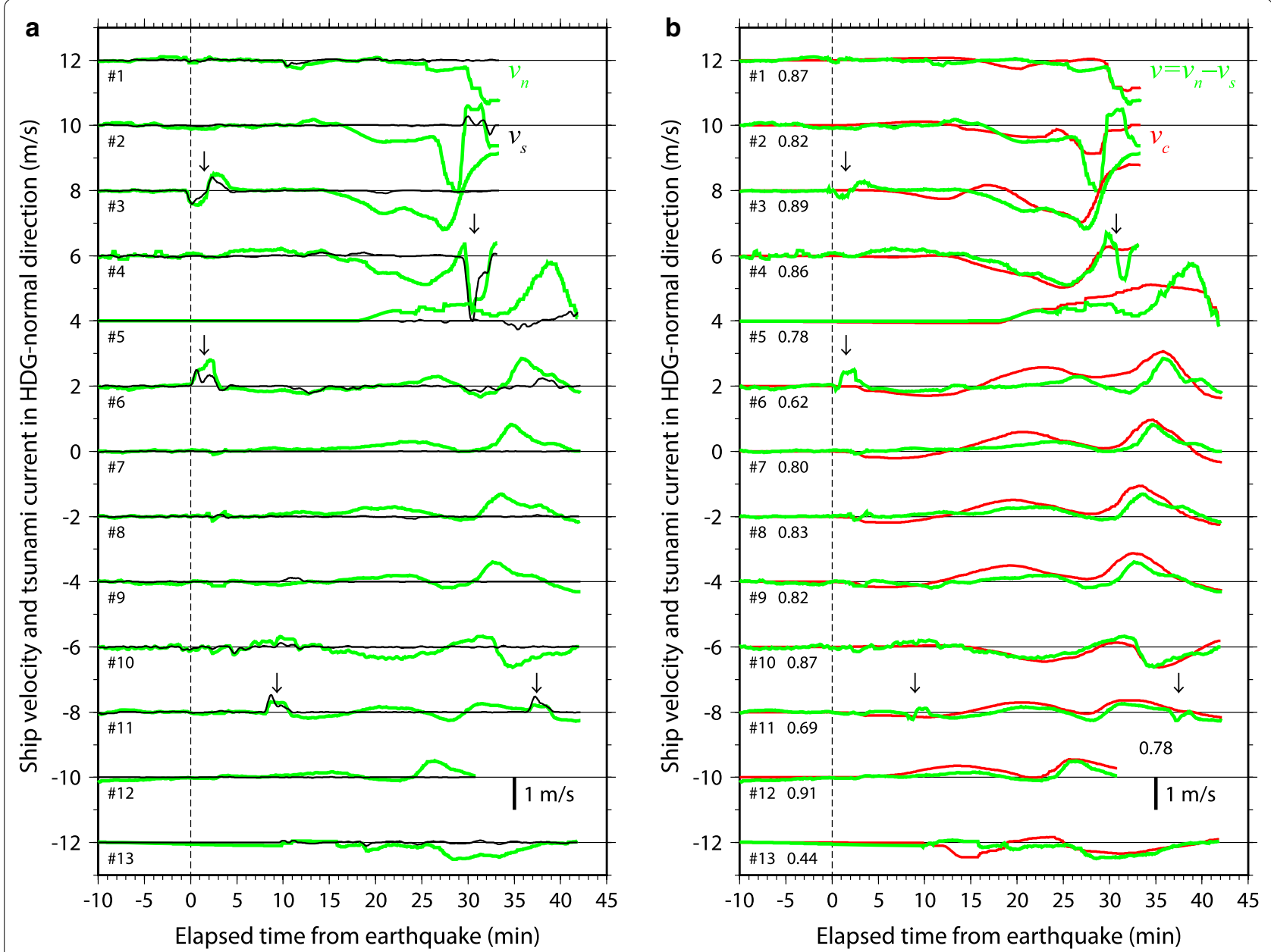

Fig. 6 Ship velocity and tsunami current in the HDG-normal direction. In a, green and black lines indicate the HDG-normal velocity shown in Fig. $3\left(v_{n}\right)$ and the apparent sway velocity due to ship yawing in Fig. $5\left(v_{s}\right)$, respectively. In $\mathbf{b}$, green and red lines indicate the corrected HDG-normal velocity $\left(v=v_{n}-v_{s}\right)$ and the simulated tsunami current $\left(v_{c}\right)$ shown in Fig. $3 b$, respectively. Arrows indicate periods where $v_{s}$ is relatively large in $\mathbf{a}$ and is effectively corrected in $\mathbf{b}$. Correlation coefficients between $v$ and $v_{c}$ are attached in the same way as in Fig. 3

(Fig. 3). The correction is expected to be relatively effective in order to find smaller tsunami signals.

Thus, the HDG-normal velocity could be separated into two components: one is the ship response to external force (tsunami current), and the other is the apparent sway velocity due to ship yawing.

Here, $A \sim 1.0$ is roughly employed. However, as mentioned above, this coefficient is essentially variable, depending on forward speed, ROT, and so on. Although it was noted above that the GNSS antenna with the navigation bridge is located at the back for many commercial ships, the position of the GNSS antenna actually depends on respective ships. So, $A$ should be adaptively determined as a temporally changing variable for each vessel. It may need further work to propose a method to adaptively obtain the coefficient using time series with a certain time length.

\section{Simulating ship response and tsunami current}

The corrected HDG-normal velocity is still not certainly the tsunami current in this direction (Fig. 6b). The corrected HDG-normal velocity should be exactly the ship response to the tsunami current. An equation of motion of a floating body was derived to examine an analytical response of the ship (Inazu et al. 2018). Here, the equation of motion is again used to estimate the ship response to the tsunami current in the HDG-normal direction:

$$
\begin{aligned}
& \frac{\partial}{\partial t}\left(v_{c}-v\right)=-\lambda\left|v_{c}-v\right|\left(v_{c}-v\right), \\
& \lambda=\frac{1}{2} \frac{C_{\mathrm{D}}}{C_{\mathrm{M}}} \frac{1}{B},
\end{aligned}
$$


where $v$ and $v_{c}$ are ship response velocity and tsunami current, respectively. $C_{\mathrm{D}}$ and $C_{\mathrm{M}}$ are constant coefficients of drag force and inertia force (Dean and Dalrymple 1985; Reddy and Swamidas 2013). B is the breadth of the ship. As described in the equations (2)-(4) in Inazu et al. (2018), the ship mass is proportional to the product of length, draft, and breadth of the ship, and the drag force in the HDG-normal direction is proportional to the product of length and draft of the ship. Thus, the ship acceleration in this direction is only dependent on the ship breadth, or proportional to $1 / B$.

The differential Eq. (2) is implemented using a fourthorder Runge-Kutta method to numerically calculate $v$ and $v_{c}$. When $v_{c}$ is given, $v$ is simulated. Conversely, when $v$ is given, $v_{c}$ can be simulated as well.

Figure 7 shows a result of a test numerical experiment. Parameters are assumed as follows: $C_{\mathrm{D}}=1, C_{\mathrm{M}}=2$, and $B=20 \mathrm{~m}$. First, tsunami current $\left(v_{c}\right)$ is given as an arbitrary input. The ship response $\left(v^{\prime}\right)$ can be simulated. There is a reasonable ship response $\left(v^{\prime}\right)$ to a steep tsunami current $\left(v_{c}\right)$ (Fig. 7a). While $v_{c}$ is forced by arbitrarily changes, $v_{c}-v^{\prime}$ reduces to be asymptotically zero (Fig. 7b). The response of $v^{\prime}$ is understandable as indicated by Fig. 6 of Inazu et al. (2018). Next, the tsunami current $\left(v_{c}^{\prime}\right)$ can be conversely simulated from the simulated ship response $\left(v^{\prime}\right)$. Prime marks (e.g., $v_{c}^{\prime}$ and $v^{\prime}$ ) indicate simulations. $v_{c}$ and $v_{c}{ }^{\prime}$ should be precisely consistent according to the analytical solution. In the test

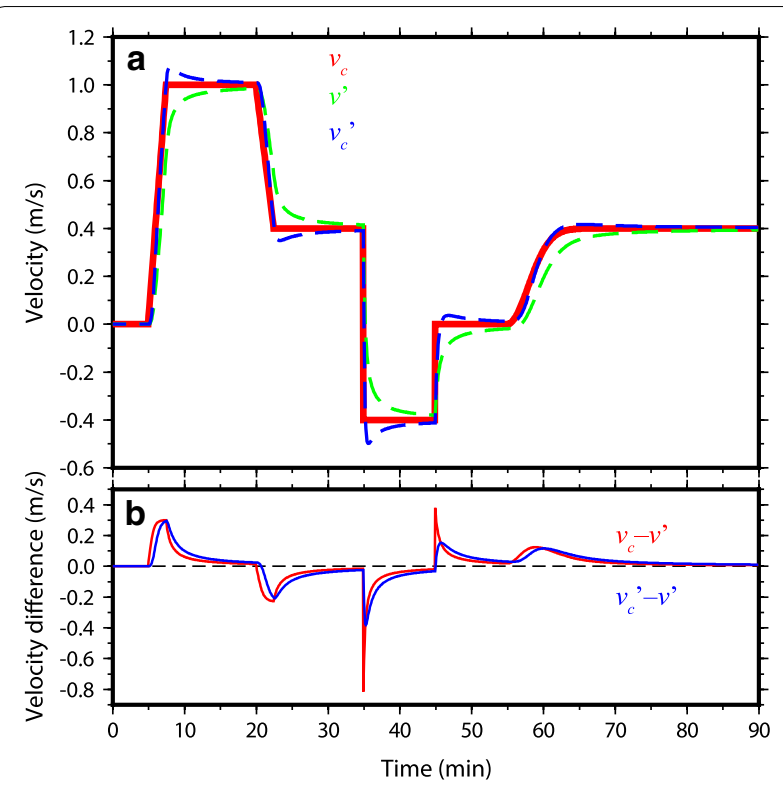

Fig. 7 Test numerical simulation based on Eq. (2). In a, red, green, and blue lines indicate tsunami current given arbitrarily $\left(v_{c}\right)$, ship response $\left(v^{\prime}\right)$ simulated from $v_{c^{\prime}}$ and tsunami current $\left(v_{c}^{\prime}\right)$ simulated from $v^{\prime}$, respectively. In $\mathbf{b}$, red and blue indicate $v_{c}-v^{\prime}$ and $v_{c}^{\prime}-v^{\prime}$, respectively experiment, $v_{c}$ includes both abrupt (times at 35 and $45 \mathrm{~min}$ ) and moderate (other times) changes. Although there are numerical errors between $v_{c}$ and $v_{c}{ }^{\prime}$ probably due to the used differential method, $v_{c}{ }^{\prime}$ mostly agrees $v_{c}$ during the moderate changes in $v_{c}$. The errors tend to be distinct during the abrupt changes in $v_{c}$. Even the fourthorder differentiation has difficulty in perfectly representing such abrupt changes that may be suitably represented by high-order components.

This method is applied to the data in Fig. 6b. Two simulations are carried out. One is that the tsunami current $\left(v_{c}\right)$ is used to simulate the ship response $\left(v^{\prime}\right)$ (Fig. 8a). The other is that the corrected HDG-normal velocity $\left(v=v_{\mathrm{n}}-v_{\mathrm{s}}\right)$ is used to simulate the tsunami current $\left(v_{c}{ }^{\prime}\right)$ (Fig. 8b). In a practical application, we expect that $v$ is calculated from AIS data, and $v_{c}{ }^{\prime}$ is estimated from $v . B$ is taken from each ship (Table 1). Simply, $C_{\mathrm{D}}=1$ and $C_{\mathrm{M}}=2$ are assumed.

We see estimated ship velocity $\left(v^{\prime}\right)$ in the HDG-normal direction responds to tsunami current $\left(v_{c}\right)$ with a response time less than a few minutes (Fig. 8a). Estimated tsunami current $\left(v_{c}{ }^{\prime}\right)$ to force the ship velocity $(v)$ seems to be reasonable as well (Fig. 8b). Then, ideal results are $v_{c}^{\prime}=v_{c}$, and $v^{\prime}=v$. Correlation coefficients between $v_{c}^{\prime}$ and $v_{c}$ are found to be better than those between $v$ and $v_{c}$ for $7 / 13$ ships, and the mean correlation coefficient may be slightly improved to 0.80 from 0.78 , but these improvements are not so significant (Figs. 6 and 8b). Correlation coefficients between $v^{\prime}$ and $v$ were better than $v$ and $v_{c}$ for $8 / 13$ ships, and the mean correlation coefficient is as much as 0.78 (Figs. 6 and 8a). When $v_{c}$ is derived from Saito et al. (2011), the mean correlation coefficients between $v_{c}{ }^{\prime}$ and $v_{c}$ and between $v^{\prime}$ and $v$ both perversely get worse to 0.71 and 0.70 , respectively (Additional file 1 : Figs. S2 and S3). The differences in the correlation coefficients between Fig. 8 and Additional file 1: Fig. S3 are small in terms of the waveforms but are attributed to slight phase deviations ( $<$ a few minutes) which are probably caused by the difference between the initial conditions of the two models. A dynamic generation process during $3 \mathrm{~min}$ was carefully involved in the initial tsunami condition by Hossen et al. (2015). Only the tsunami simulation using the dynamic initial condition possibly yielded slightly better representations of $v_{c}^{\prime}$ (and $v^{\prime}$ ) (Fig. 8). Perhaps, the simulation considering the ship response by Eq. (2) potentially works to estimate tsunami current from AIS data. However, to clearly confirm that other conditions should be simultaneously improved.

Following factors that are uncertain and/or incomplete should be also considered to better represent $v_{c}{ }^{\prime}$ and $v^{\prime}$. Numerical errors in the numerical simulations for the ship response may not always be negligible in particular for discontinuous changes of the tsunami (Fig. 7). 

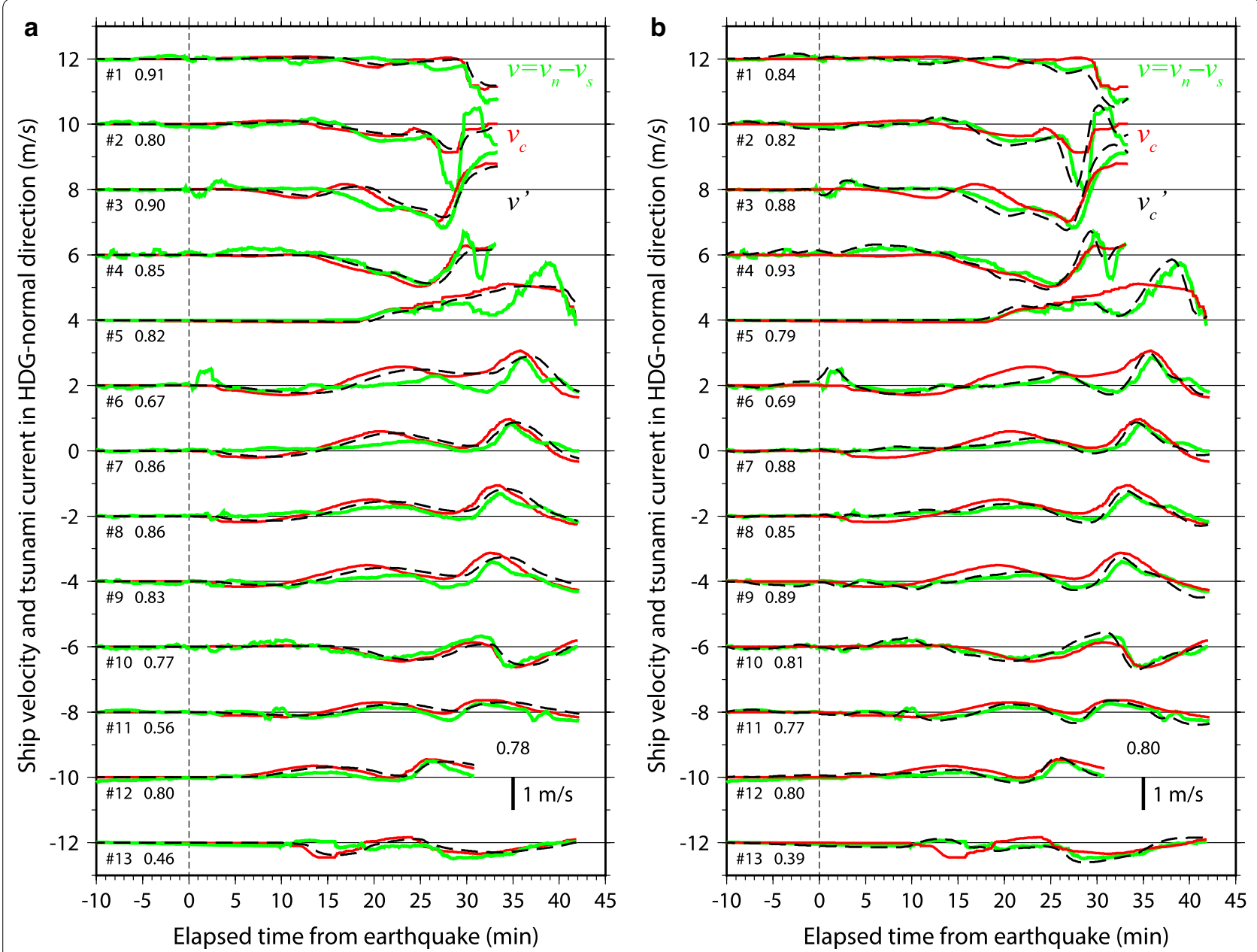

Fig. 8 Ship velocity and tsunami current in the HDG-normal direction. In both $\mathbf{a}$ and $\mathbf{b}$, green and red indicate the corrected HDG-normal velocity $\left(v=v_{n}-v_{s}\right)$ and the simulated tsunami current $\left(v_{c}\right)$ shown in Fig. 6b, respectively. Dashed lines indicate ship response $\left(v^{\prime}\right)$ simulated from $v_{c}$ in $(\mathbf{a})$, and tsunami current $\left(v_{c}^{\prime}\right)$ simulated from the ship velocity $\left(v=v_{n}-v_{s}\right)$ in $\mathbf{b}$, respectively. Correlation coefficients are shown between $v$ and $v^{\prime}$ in $\mathbf{a}$ and between $v_{c}$ and $v_{c}^{\prime}$ in $\mathbf{b}$, respectively

The equation of motion used was useful to understand essential behaviors between tsunami current and ship response, but the equation may be too simplified. Equation (2) may be better to take into account a total velocity that simultaneously considers both the HDG-normal and HDG-parallel velocities, because of non-linearity of the equation. These may modify $C_{\mathrm{D}}$ and $C_{\mathrm{M}}$ (Sarpkaya and Isaacson 1981; Dean and Dalrymple 1985; Reddy and Swamidas 2013). Equations for ship maneuvering (Yasukawa and Yoshimura 2015; Perara 2017) may be useful to rigorously simulate ship behaviors. However, they need a number of parameters, and much of them are not available in AIS data.

At this moment, we note that the correction using the yawing effect is first necessary to obtain clearer tsunami current signals from AIS data (Fig. 6). Although the estimation of the tsunami current from the corrected
HDG-normal velocity using Eq. (2) is also reasonable in principle, this operation yielded a slight improvement, and then will be a secondary correction (Fig. 8b). Other factors mentioned above including accuracy of tsunami source probably involve certain amounts of uncertainties in estimating the tsunami current using the equation of ship motion.

\section{Detectability of tsunami currents from AIS data}

We have clearly found tsunami currents greater than $\sim 1.0 \mathrm{~m} / \mathrm{s}$ in the HDG-normal direction (Figs. 4 and 6). The detectability of tsunami currents from AIS data is discussed. According to Figs. 4 and Additional file 1: Fig. $\mathrm{S} 1$, when $|\mathrm{COG}-\mathrm{HDG}|>5^{\circ}$, it is quite extraordinary. SOG is typically $5-10 \mathrm{~m} / \mathrm{s}$.

To examine the detectability of the tsunami whose time scales are mostly less than $1 \mathrm{~h}$, we calculated standard 
deviations (sigma) of COG-HDG during $2 \mathrm{~h}$ before the earthquake, and they were $0.3-1.0^{\circ}$ (Table 1). Based on a three-sigma limit, when $|\mathrm{COG}-\mathrm{HDG}|$ is greater than $1.0-3.0^{\circ}$, they should be fairly extraordinary. Similarly, the three-sigma limits of $v=v_{\mathrm{n}}-v_{\mathrm{s}}$ were $0.1-0.3 \mathrm{~m} / \mathrm{s}$, which should be lower limits of tsunami current detection using current AIS data (Table 1). According to the small-amplitude water-wave theory, the relationship between horizontal water velocity and tsunami height is well-known when the long-wave approximation is assumed (Dean and Dalrymple 1985):

$$
v=\eta \sqrt{\frac{g}{h}},
$$

where $v$ is long-wave tsunami current speed, $\eta$ tsunami height, $h$ water depth, and $g$ gravity acceleration. When $v=0.1-0.3 \mathrm{~m} / \mathrm{s}$ and $h=100 \mathrm{~m}$ are assumed with $g=9.8 \mathrm{~m} / \mathrm{s}^{2}$, an equivalent tsunami height is $\eta=0.3-$ $1.0 \mathrm{~m}$. Once offshore tsunami height is estimated, coastal tsunami height is shortly calculated using a kind of Green's law. According to experiences of offshore and coastal tsunami height observations for several earthquakes (Hayashi 2010), we note that tsunami currents due to near-field megathrust earthquakes whose moment magnitudes are greater than about 8 will be suitably detected by current AIS data.

A survey by Reynolds (2012) reported that a container ship in offshore navigation showed $|\mathrm{COG}-\mathrm{HDG}|<5^{\circ}$ in most cases during days. Our analysis of the three-sigma limits of $|C O G-H D G|$ was $1.0-3.0^{\circ}$, which is roughly smaller than $5^{\circ}$. This is reasonable since our analysis was carried out using only 2 -h time series for the tsunami detection.

\section{Summary}

The AIS data during the 2011 Tohoku tsunami were investigated in detail after Inazu et al. (2018). Ship velocity during offshore navigation strongly deviated with mostly equivalent tsunami current velocity not only for the heading-normal direction but also for the headingparallel direction. The heading-normal velocity of the ship was affected by the heading rotation because the pivot point of the heading and the GNSS antenna are separately located with a distance comparable to the ship length. This effect was suitably corrected, and the corrected heading-normal velocity showed better agreement with simulated tsunami currents. However, the corrected heading-normal velocity was still not tsunami current itself, and should be exactly the ship response to the tsunami current. Based on a theoretical equation of motion of a floating vessel, we could numerically estimate tsunami current from the corrected heading-normal velocity. Improvements were very slight or not so significant in correlation between the estimated tsunami current and tsunami wave simulation, probably because other uncertainties including tsunami source model might affected in estimating the tsunami current. At this moment, the heading-normal velocity derived from AIS data will be more suitably used for tsunami current meters once the yawing effect is corrected. We expect to find tsunami currents of tens of centimeters per second using AIS, and hope to examine smaller tsunamis.

\section{Supplementary information}

Supplementary information accompanies this paper at https://doi. org/10.1186/s40623-020-01165-7.

Additional file 1: Fig. S1. Time series of AIS data of nine vessels (\#1, \#4, $\# 6, \# 7, \# 8, \# 9, \# 10, \# 12$, and \#13). See also Fig. 4. Fig. S2. Corrected HDGnormal velocity (green) and tsunami current simulation (red) using the initial condition of Saito et al. (2011). Compare to Fig. 6b. Fig. S3. Same as Fig. 8 but $v c$ is calculated by tsunami current simulation using the initial condition of Saito et al. (2011).

\section{Abbreviations}

AIS: Automatic Identification System; SOG: Speed over ground; COG: Course over ground; HDG: Heading; ROT: Rate of turn; GNSS: Global Navigation Satellite System; IMO: International Maritime Organization; ITU: International Telecommunication Union; IEC: International Electrotechnical Commission.

\section{Acknowledgements}

We thank two anonymous reviewers for their constructive comments that greatly improved the manuscript. The AIS data used in this study were compiled by IHS Maritime \& Trade.

\section{Authors' contributions}

DI analyzed data, carried out simulations, and wrote the paper. DI, TIk, TIs, and TW discussed the ship motion with tsunamis. All authors read and approved the final manuscript.

Funding

This study was supported by JSPS KAKENHI Grant number 18K04654.

Availability of data and materials

Please contact the corresponding author for data requests.

\section{Competing interests}

The authors declare that they have no competing interest.

\section{Author details}

${ }^{1}$ Department of Marine Resources and Energy, Tokyo University of Marine Science and Technology, 4-5-7 Konan, Minato, Tokyo 108-8477, Japan. ${ }^{2}$ Department of Maritime Systems Engineering, Tokyo University of Marine Science and Technology, 2-1-6 Etchujima, Koto, Tokyo 135-8533, Japan. ${ }^{3}$ Graduate School of Frontier Sciences, The University of Tokyo, 5-1-5 Kashiwanoha, Kashiwa, Chiba 277-8563, Japan.

Received: 4 February 2020 Accepted: 17 March 2020

Published online: 31 March 2020

\section{References}

Anderson KD (2000) Determination of water level and tides using interferometric observations of GPS signals. J Atmos Ocean Technol 17:11181127. https://doi.org/10.1175/1520-0426(2000)017\%3c1118:DOWLA T\%3e2.0.CO;2 
Baba T, Allgeyer S, Hossen J, Cummins PR, Tsushima H, Imai K, Yamashita K, Kato T (2017) Accurate numerical simulation of the far-field tsunami caused by the 2011 Tohoku earthquake, including the effects of Boussinesq dispersion, seawater density stratification, elastic loading, and gravitational potential change. Ocean Modell 111:46-54. https://doi. org/10.1016/j.ocemod.2017.01.002

Benjamin LR, Flament P, Cheung KF, Luther DS (2016) The 2011 Tohoku tsunami south of Oahu: high-frequency Doppler radio observations and model simulations of currents. J Geophys Res Oceans 121:1133-1144. https://doi.org/10.1002/2015JC011207

Bernard EN, Mofjeld HO, Titov V, Synolakis CE, González Fl (2006) Tsunami: scientific frontiers, mitigation, forecasting and policy implications. Philos Trans R Soc A 364:1989-2007. https://doi.org/10.1098/rsta.2006.1809

Bricker JD, Munger S, Pequignet C, Wells JR, Pawlak G, Cheung KF (2007) ADCP observations of edge waves off Oahu in the wake of the November 2006 Kuril Islands tsunami. Geophys Res Lett 34:L23617. https://doi. org/10.1029/2007GL032015

Cardellach E, Rius A, Martín-Neira M, Fabra F, Nogués-Correig O, Ribó S, Kainulainen J, Camps A, D'Addio S (2014) Consolidating the precision of interferometric GNSS-R ocean altimetry using airborne experimental data. IEEE Trans Geosci Remote Sens 52:4992-5004. https://doi.org/10.1109/ TGRS.2013.2286257

Carson-Jackson J (2012) Satellite AIS—developing technology or existing capability? J Navig 65:303-321. https://doi.org/10.1017/S037346331 100066X

Chadwell CD, BockY (2001) Direct estimation of absolute precipitable water in oceanic regions by GPS tracking of a coastal buoy. Geophys Res Lett 28:3701-3704. https://doi.org/10.1029/2001GL013280

Chihara Y (1969) On the location of the navigation bridge on giant ship. Jpn J Ergonom 5:349-355. https://doi.org/10.5100/jje.5.349 (in Japanese)

Clarizia MP, Ruf C, Cipollini P, Zuffada C (2016) First spaceborne observation of sea surface height using GPS-reflectometry. Geophys Res Lett 43:767-774. https://doi.org/10.1002/2015GL066624

Clark IC (2005) Steering and the action of a ship's rudder. In: Ship dynamics for mariners. A guide to the theory of hull resistance, power requirements, propulsion, steering, control systems and ship motion in a seaway, 1st edn. The Nautical Institute, London, pp 109-144

Dean RG, Dalrymple RA (1985) Water wave mechanics for engineers and scientists, vol 2. Advanced series on ocean engineering. World Scientific Publishing, Singapore. https://doi.org/10.1142/1232

Dzvonkovskaya A, Petersen L, Helzel T, Kniephoff M (2018) High-frequency ocean radar support for Tsunami Early Warning Systems. Geosci Lett 5:29. https://doi.org/10.1186/s40562-018-0128-5

Eble MC, Gonzalez FI (1991) Deep-ocean bottom pressure measurements in the Northeast Pacific. J Phys Oceanogr 8:221-233. https://doi. org/10.1175/1520-0426(1991)008\%3c0221:DOBPM|\%3e2.0.CO;2

Eriksen T, Skauen AN, Narheim B, Helleren $\varnothing$, Olsen $\varnothing$, Olsen RB (2010) Tracking ship traffic with space-based AIS: experience gained in first months of operations. In: 2010 Int Water Side Sec Conf 11874359. https://doi. org/10.1109/WSSC.2010.5730241

Filloux JH (1983) Pressure fluctuations on the open-ocean floor off the Gulf of California: tides, earthquakes, tsunamis. J Phys Oceanogr 13:783796. https://doi.org/10.1175/1520-0485(1983)013\%3c0783:PFOTO O\%3e2.0.CO;2

Foster JH, Carter GS, Merrifield MA (2009) Ship-based measurements of sea surface topography. Geophys Res Lett 36:L11605. https://doi. org/10.1029/2009GL038324

Foster JH, Brooks BA, Wang D, Carter GS, Merrifield MA (2012) Improving tsunami warning using commercial ships. Geophys Res Lett 39:L09603. https ://doi.org/10.1029/2012GL051367

Godin OA, Irisov VG, Leben RR, Hamlington BD, Wick GA (2009) Variations in sea surface roughness induced by the 2004 Sumatra-Andaman tsunami. Nat Hazards Earth Syst Sci 9:1135-1147. https://doi.org/10.5194/nhess -9-1135-2009

Hashimoto N, Mitsui M, Goda Y, Nagai T, Takahashi T (1996) Improvement of submerged Doppler-type directional wave meter and its application to field observation. In: Proc 25th Int Conf Coast Eng, pp 629-642. https:// doi.org/10.1061/9780784402429.050

HayashiY (2010) Empirical relationship of tsunami height between offshore and coastal stations. Earth Planets Space 62:269-275. https://doi. org/10.5047/eps.2009.11.006
Hinata H, Fujii S, Furukawa K, Kataoka T, Miyata M, Kobayashi T, Mizutani M, Kokai T, Kanatsu N (2011) Propagating tsunami wave and subsequent resonant response signals detected by HF radar in the Kii Channel, Japan. Estuar Coast Shelf Sci 95:268-273. https://doi.org/10.1016/j. ecss.2011.08.009

Hino R, Ito Y, Ohta Y, linuma T, Inazu D (2013) Ocean bottom pressure records of the 2011 Tohoku-Oki earthquake. In: Proc 11th SEGJ Int Symp, pp 462-465. https://doi.org/10.1190/segj112013-117

Hirobe T, Niwa Y, Endoh T, Mulia IE, Inazu D, Yoshida T, Tatehata H, Nadai A, Waseda T, Hibiya T (2019) Observation of sea surface height using airborne radar altimetry: a new approach for large offshore tsunami detection. J Oceanogr 75:541-558. https://doi.org/10.1007/s10872-01900521-w

Horiuchi K, Kano T, Miyazawa Y, Sato K, Murata A (2015) Improvement of current forecast by assimilating observed ship drift data. In: Proc Jpn Soc Naval Arch Ocean Eng, vol 21, pp 67-69. https://doi.org/10.14856/ conf.21.0_67 (in Japanese)

Hossen MJ, Cummins PR, Dettmer J, Baba T (2015) Tsunami waveform inversion for sea surface displacement following the 2011 Tohoku earthquake: importance of dispersion and source kinematics. J Geophys Res Solid Earth 120:6452-6473. https://doi.org/10.1002/2015JB011942

Høye GK, Eriksen T, Meland BJ, Narheim BT (2008) Space-based AIS for global maritime traffic monitoring. Acta Astronaut 62:240-245. https://doi. org/10.1016/j.actaastro.2007.07.001

Ichikawa K, Ebinuma T, Konda M, Yufu K (2019) Low-cost GNSS-R altimetry on a UAV for water-level measurements at arbitrary times and locations. Sensors 19:998. https://doi.org/10.3390/s19050998

Inazu D, Waseda T, Hibiya T, Ohta Y (2016) Assessment of GNSS-based height of multiple ships for measuring and forecasting great tsunamis. Geosci Lett 3:25. https://doi.org/10.1186/s40562-016-0059-y

Inazu D, Ikeya T, Waseda T, Hibiya T, Shigihara Y (2018) Measuring offshore tsunami currents using ship navigation records. Prog Earth Planet Sci 5:38. https://doi.org/10.1186/s40645-018-0194-5

Intergovernmental Oceanographic Commission (IOC) (2006) Manual on sea level measurements and interpretation, vol IV: an update to 2006. JCOMM Tech Rep No 31; WMO/TD. No 1339, 80 pp, UNESCO, Paris, France

International Electrotechnical Commission (IEC) (2018) Maritime navigation and radiocommunication equipment and systems-automatic identification systems (AIS) - part 2: class A shipborne equipment of the universal automatic identification system (AIS) —operational and performance requirements, methods of test and required test results. IEC 61993-2:2018 RLV

International Maritime Organization (IMO) (1998) Recommendation on Performance Standards for an Universal Shipborne Automatic Identification System (AIS). Resolution MSC, vol 74, no 69, Annex 3

International Maritime Organization (IMO) (2002) Guidelines for the onboard operational use of shipborne Automatic Identification Systems (AIS). Resolution A, vol 917, no 22

International Maritime Organization (IMO) (2016) Revised guidelines for the onboard operational use of shipborne Automatic Identification Systems (AIS). Resolution A, vol 1106, no 29

International Telecommunication Union (ITU) (2014) Technical characteristics for an automatic identification system using time division multiple access in the VHF maritime mobile frequency band. Rec. ITU-R M. 1371-5

Joseph A (2011) Tsunamis: detection, monitoring, and early-warning technologies. Academic Press, Oxford, p 436. https://doi.org/10.1016/C2010 $-0-65652-5$

Kanazawa T, Uehira K, Mochizuki M, Shinbo T, Fujimoto H, Noguchi S, Kunugi T, Shiomi K, Aoi S, Matsumoto T, Sekiguchi S, Okada Y (2016) S-net project, cabled observation network for earthquakes and tsunamis. SubOptic 2016, WE2B-3

Kaneda Y, Kawaguchi K, Araki E, Matsumoto H, Nakamura T, Kamiya S, Ariyoshi K, Hori T, Baba T, Takahashi N (2015) Development and application of an advanced ocean floor network system for megathrust earthquakes and tsunamis. In: Favali P, Beranzoli L, De Santis A (eds) Seafloor observatories. Springer, Berlin, pp 643-662. https://doi.org/10.1007/978-3-642-11374 -1 25

Kato T, Terada Y, Tadokoro K, Kinugasa N, Futamura A, Toyoshima M, Yamamoto S, Ishii M, Tsugawa T, Nishioka M, Takizawa K, Shoji Y, Seko H (2018) Development of GNSS buoy for a synthetic geohazard monitoring system. J Disaster Res 13:460-471. https://doi.org/10.20965/jdr.2018.p0460 
Kawai H, Satoh M, Kawaguchi K, Seki K (2013) Characteristics of the 2011 Tohoku tsunami waveform acquired around Japan by NOWPHAS equipment. Coast Eng J 55:1350008. https://doi.org/10.1142/S0578563413500083

Kijima K, Katsuno T, Nakiri Y, Furukawa Y (1990) On the manoeuvring performance of a ship with the parameter of loading condition. J Soc Naval Arch Jpn 168:141-148. https://doi.org/10.2534/jjasnaoe1968.1990.168_141

Lacy JR, Rubin DM, Buscombe D (2012) Currents, drag, and sediment transport induced by a tsunami. J Geophys Res Oceans 117:C09028. https://doi. org/10.1029/2012JC007954

Larson KM, Ray RD, Williams SDP (2017) A 10-year comparison of water levels measured with a geodetic GPS receiver versus a conventional tide gauge. J Atmos Ocean Technol 34:295-307. https://doi.org/10.1175/JTECH -D-16-0101.1

Löfgren JS, Haas R (2014) Sea level measurements using multi-frequency GPS and GLONASS observations. EURASIP J Adv Sig Process 50:2014. https://doi. org/10.1186/1687-6180-2014-50

Lowe ST, Zuffada C, Chao Y, Kroger P, Young LE, LaBrecque JL (2002) 5-cmPrecision aircraft ocean altimetry using GPS reflections. Geophys Res Lett 29:1375. https://doi.org/10.1029/2002GL014759

Mashburn J, Axelrad P, Lowe ST, Larson KM (2018) Global ocean altimetry with GNSS reflections from TechDemoSat-1. IEEE Trans Geosci Remote Sens 56:4088-4097. https://doi.org/10.1109/TGRS.2018.2823316

Masuda K, Hara D, Nishizawa K (2014) An overview of the AIS, and configuration of the data. Navigation 188:6-16. https://doi.org/10.18949/jinnavi.188.0_6 (in Japanese)

Míguez BM, Gómez BP, Fanjul EA (2005) The ESEAS-Rl sea level test station: reliability and accuracy of different tide gauges. Int Hydrogr Rev 6:44-53

Miyazawa Y, Guo X, Varlamov SM, Miyama T, Yoda K, Sato K, Kano T, Sato K (2015) Assimilation of the seabird and ship drift data in the north-eastern sea of Japan into an operational ocean nowcast/forecast system. Sci Rep 5:17672. https://doi.org/10.1038/srep17672

Mulia IE, Hirobe T, Inazu D, Endoh T, Niwa Y, Gusman AR, Tatehata H, Waseda T, Hibiya T (2020) Advanced tsunami detection and forecasting by radar on unconventional airborne observing platforms. Sci Rep 10:2412. https://doi. org/10.1038/s41598-020-59239-1

Mungov G, Eblé M, Bouchard R (2013) DART ${ }^{\circledR}$ Tsunameter retrospective and real-time data: a reflection on 10 years of processing in support of tsunami research and operations. Pure Appl Geophys 170:1369-1384. https://doi. org/10.1007/s00024-012-0477-5

Namegaya Y, Tanioka Y, Abe K, Satake K, Hirata K, Okada M, Gusman AR (2009) In situ measurements of tide gauge response and corrections of tsunami waveforms from the Niigataken Chuetsu-oki earthquake in 2007. Pure Appl Geophys 166:97-116. https://doi.org/10.1007/s00024-008-0441-6

Okal EA, Piatanesi A, Heinrich P (1999) Tsunami detection by satellite altimetry. J Geophys Res Solid Earth 104:599-615. https://doi.org/10.1029/1998JB0000 18

Ozaki (2012) JMA's tsunami warning for the 2011 Great Tohoku Earthquake and tsunami warning improvement plan. J Disaster Res 7:439-445. https://doi. org/10.20965/jdr.2012.p0439

Perara LP (2017) Navigation vector based ship maneuvering prediction. Ocean Eng 138:151-160. https://doi.org/10.1016/j.oceaneng.2017.04.017

Pugh DT (1972) The physics of pneumatic tide gauges. Int Hydrogr Rev 49:71-97

Rabinovich AB, Eblé MC (2015) Deep-ocean measurements of tsunami waves. Pure Appl Geophys 172:3281-3312. https://doi.org/10.1007/s0002 4-015-1058-1

Rabinovich AB, Thomson RE, Stephenson FE (2006) The Sumatra tsunami of 26 December 2004 as observed in the North Pacific and North Atlantic oceans. Surv Geophys 27:647-677. https://doi.org/10.1007/s10712-006-9000-9

Reddy DV, Swamidas ASJ (2013) Essentials of offshore structures_framed and gravity platforms, 1st edn. CRC Press, Boca Raton. https://doi.org/10.1201/ b15033

Reynolds RM (2012) Comparison of INS heading and GPS COG. RMRTech Memo $\# 1227$

Roarty H, Cook T, Hazard L, George D, Harlan J, Cosoli S, Wyatt L, Alvarez Fanjul E, Terrill E, Otero M, Largier J, Glenn S, Ebuchi N, Whitehouse B, Bartlett K, Mader J, Rubio A, Corgnati L, Mantovani C, Griffa A, Reyes E, Lorente P, FloresVidal X, Saavedra-Matta KJ, Rogowski P, Prukpitikul S, Lee S-H, Lai J-W, Guerin C-A, Sanchez J, Hansen B, Grilli S (2019) The global high frequency radar network. Front Mar Sci 6:164. https://doi.org/10.3389/fmars.2019.00164
Roggenbuck O, Reinking J, Härting A (2014) Oceanwide precise determination of sea surface height from in situ measurements on cargo ships. Mar Geod 37:77-96. https://doi.org/10.1080/01490419.2013.868385

Ruffini G, Soulat F, Caparrini M, Germain O, Martín-Neira M (2004) The Eddy experiment: accurate GNSS-R ocean altimetry from low altitude aircraft. Geophys Res Lett 31:L12306. https://doi.org/10.1029/2004GL019994

Saito T, Ito Y, Inazu D, Hino R (2011) Tsunami source of the 2011 Tohoku-Oki earthquake, Japan: inversion analysis based on dispersive tsunami simulations. Geophys Res Lett 38:L00G19. https://doi.org/10.1029/2011GL049089

Sarpkaya T, Isaacson M (1981) Mechanics of wave forces on offshore structures. Van Norstrand, Reinhold, New York

Satake K (2007) Tsunamis, Chapter 4.17. In: Treatise on geophysics, vol 4, Elsevier, Amsterdam, pp 483-511. https://doi.org/10.1016/B978-044452748-6.00078 $-X$

Satake K, Okada M, Abe K (1988) Tide gauge response to tsunamis: measurements at 40 tide gauge stations in Japan. J Mar Res 46:557-571. https://doi. org/10.1357/002224088785113504

Seo S-G, Mishu M (2011) The use of pivot point in ship handling for safer and more accurate ship manoeuvring. Proc IMLA 1(29):271-280

Sobarzo M, Garcés-Vargas J, Bravo L, Tassara A, Quiñones RA (2012) Observing sea level and current anomalies driven by a megathrust slope-shelf tsunami: the event on February 27, 2010 in central Chile. Cont Shelf Res 49:44-55. https:// doi.org/10.1016/j.csr.2012.09.001

Song YT, Fukumori I, Shum CK, Yi Y (2012) Merging tsunamis of the 2011 TohokuOki earthquake detected over the open ocean. Geophys Res Lett 39:L05606. https://doi.org/10.1029/2011GL050767

Takayama T, Hashimoto N, Nagai T, Takahashi T, Sasaki H, Ito Y (1994) Development of a submerged Doppler-type directional wave meter. In: Proc 24th Int Conf Coast Eng , pp 624-634. https://doi.org/10.1061/9780784400890.047

Tetley L, Calcutt D (2001) Electronic navigation systems, 3rd edn. ButterworthHeinemann, Oxford

Tsushima H, Hirata K, Hayashi Y, Tanioka Y, Kimura K, Sakai S, Shinohara M, Kanazawa T, Hino R, Maeda K (2011) Near-field tsunami forecasting using offshore tsunami data from the 2011 off the Pacific coast of Tohoku Earthquake. Earth Planets Space 63:821-826. https://doi.org/10.5047/eps.2011.06.052

Tzeng C-Y (1998) Analysis of the pivot point for a turning ship. J Mar Sci Technol 6:39-44

Wickert J, Cardellach E, Martín-Neira M, Bandeiras J, Bertino L, Andersen OB, Camps A, Catarino N, Chapron B, Fabra F, Floury N, Foti F, Gommenginger C, Hatton J, Høeg P, Jäggi A, Kern M, Lee T, Li Z, Park H, Pierdicca N, Ressler G, Rius A, Roselló J, Saynisch J, Soulat F, Shum CK, Semmling M, Sousa A, Xie J, Zuffada C (2016) GEROS-ISS: GNSS REflectometry, radio occultation, and scatterometry onboard the international space station. IEEE J Sel Top Appl Earth Obs Remote Sens 9:4552-4581. https://doi.org/10.1109/JSTAR S.2016.2614428

Woodworth PL, Smith DE (2003) A one year comparison of radar and bubbler tide gauges at Liverpool. Int Hydrogr Rev 4:42-49

Woodworth PL, et al (ed) (2016) Manual on sea-level measurements and interpretation, vol V: Radar Gauges; supplement: practical experiences. (IOC Manuals and Guides No 14, vol V, JCOMM Tech Rep No 89). UNESCO, Paris

Wright CW, Walsh EJ, Krabill WB, Shaffer WA, Baig SR, Peng M, Pietrafesa LJ, Garcia AW, Marks FD Jr, Black PG, Sonntag J, Beckley BD (2009) Measuring storm surge with an airborne wide-swath radar altimeter. J Atmos Ocean Technol 26:2200-2215. https://doi.org/10.1175/2009JTECHO627.1

Yasukawa H, Yoshimura Y (2015) Introduction of MMG standard method for ship maneuvering predictions. J Mar Sci Technol 20:37-52. https://doi. org/10.1007/s00773-014-0293-y

Yoshimura Y, Ma N (2003) Manoeuvring prediction of fishing vessels. In: MARSIM 2003 Conf Proc pRC-29-1-10

Yoshimura Y, Masumoto Y (2011) Hydrodynamic force database with medium high speed merchant ships including fishing vessels and investigation into a manoeuvring prediction method. J J.jn Soc Naval Arch Ocean Eng 14:63-73. https://doi.org/10.2534/jjasnaoe.14.63 (in Japanese with English abstract)

\section{Publisher's Note}

Springer Nature remains neutral with regard to jurisdictional claims in published maps and institutional affiliations. 